\title{
Early cannabis use and DSM-IV nicotine dependence: a twin study
}

\author{
Arpana Agrawal', Michael T. Lynskey', Michele L. Pergadia', Kathleen K. Bucholz', \\ Andrew C. Heath', Nicholas G. Martin² \& Pamela A. F. Madden' \\ Washington University School of Medicine, Department. of Psychiatry, St Louis, MO, USA' and Queensland Institute of Medical Research, Brisbane, Australia ${ }^{2}$
}

\begin{abstract}
Background Evidence suggests that cannabis users are at increased risk for cigarette smoking - if so, this may potentially be the single most alarming public health challenge posed by cannabis use. We examine whether cannabis use prior to age 17 years is associated with an increased likelihood of DSM-IV nicotine dependence and the extent to which genetic and environmental factors contribute to this association. Methods A population-based cohort of 24-36-year-old Australian male and female twins ( $n=6257,286$ and 229 discordant pairs) was used. The co-twincontrol method, with twin pairs discordant for early cannabis use, was used to examine whether, after controlling for genetic and familial environmental background, there was evidence for an additional influence of early cannabis use on DSM-IV nicotine dependence. Bivariate genetic models were fitted to the full data set to quantify the genetic correlation between early cannabis use and nicotine dependence. Results The early cannabis-using twin was about twice as likely to report nicotine dependence, when compared to their co-twin who had experimented with cigarettes but had never used cannabis. Even when analyses were restricted to cannabis users, earlier age cannabis use onset conferred greater risk (1.7) for nicotine dependence than did later onset. This association was governed largely by common genetic liability to early cannabis use and nicotine dependence, as demonstrated by genetic correlations of 0.41-0.52. Conclusions Early-onset cannabis users are at increased risk for nicotine dependence, but this risk is attributable largely to common genetic vulnerability. There is no evidence for a causal relationship between cannabis use and nicotine dependence.
\end{abstract}

Keywords Cannabis, discordant twins, genetic, Mx, nicotine dependence, twin modeling.

Correspondence to: Arpana Agrawal, Washington University School of Medicine, Department of Psychiatry, 660 S. Euclid, Box 8134, St Louis, MO 63110, USA. E-mail: arpana@wustl.edu

Submitted 8 January 2008; initial review completed 7 May 2008; final version accepted 15 July 2008

\section{INTRODUCTION}

It is well documented that cannabis use may contribute to an increased likelihood of experimenting with other illicit drugs [1-6]. However, researchers have begun recently to question whether cannabis use is also associated with increased risk for cigarette smoking. In two longitudinal samples of adolescents, those who abstained initially from cigarettes were more likely to report cigarette smoking at a subsequent assessment if they used cannabis in the interim $[7,8]$. There is also accumulating evidence that cannabis use may impact substantially subsequent important later stages of cigarette smoking, including nicotine dependence (ND) [7-9].
Two epidemiological studies have examined 'reverse gateways'. Patton and colleagues [7], using a longitudinal sample of teens, reported that weekly cannabis use predicted an increase in tobacco initiation. The authors also reported that young adult smokers who used cannabis on a daily basis were at a nearly 3.6 increased odds of developing ND. In a sample of adolescents and young adults, Timberlake and colleagues [9] reported that 23-27-year-olds with a life-time history of cannabis use (>10 times) were twice as likely to develop ND when compared to those young adults who reported no cannabis use at all.

While these studies demonstrate an association between cannabis use and cigarette smoking, they fail to address whether a common genetic predisposition to 
cannabis use and cigarette smoking is responsible for this association, or whether this increase in risk is attributable to overlapping environmental influences. Empirical evidence demonstrates the importance of heritable influences on both cannabis use [10] and stages of cigarette smoking [11-16], but we are aware of only one genetically informative study of adult female twins, [17] which showed that the association between cannabis use and cigarette smoking (experimentation and ND) was due to a correlation between the liability to use cannabis and experimentation with cigarettes, both of which are influenced genetically $\left(h^{2}\right.$ cannabis $\left.=0.40 ; h^{2}{ }_{\text {nicotine }}=0.67\right)$, but not due to any direct influence of cannabis use on ND or vice versa.

Several studies [3-6] show that those who initiate cannabis use earlier in life are at significantly greater risk for experimentation with other illicit drugs, illicit substance use disorders and for alcohol dependence. However, it remains to be seen whether individuals who initiate cannabis use at an early age are more likely to develop ND when matched for genetic background, and possibly for some environmental influences, with individuals who do not use cannabis at all and with individuals who use cannabis but only at a later age. The study of identical and fraternal twin pairs who are matched for familial environment and for genetic background allows us to test this important hypothesis.

In the current study, we use data gathered on young adult Australian twins to explore: (i) whether cannabis use prior to age 17 (early-onset) is associated with an increased risk for onset of DSM-IV ND and (ii) the extent to which this association between early onset cannabis use and DSM-IV ND is explained by genetic and environmental commonality.

\section{MATERIALS AND METHODS}

\section{Sample}

A sample of 6257 adult Australian male and female twins that included monozygotic (MZ) and dizygotic (DZ) pairs as well as twins from incomplete pairs (although these single-twins were not informative for the discordant twin pair analyses) were used. The full paired sample consisted of $494 \mathrm{MZ}$ and $395 \mathrm{DZ}$ same-sex male pairs and of $698 \mathrm{MZ}$ and 513 DZ same-sex female pairs. Data on 661 DZ opposite sex pairs and 736 twins from pairs where a co-twin did not participate was also available. While opposite-sex pairs and single twins could not be used for the discordant twin pair analyses, data from these twins were utilized for twin analyses. Twins were aged 24-36 [mean $30(2.5)]$ years at the time of interviews conducted in 1996-2000, and these data alone were used for the analyses presented here. All twins were born between
1964 and 1971 and were recruited initially through the Australian school systems and via mass media appeals. Parents registered the adolescent twins initially in 1980-82 and the twins themselves were interviewed via telephone in 1996-2000, after informed consent, as approved by the Institutional Review Boards of the Washington University in St Louis, USA and the Queensland Institute of Medical Research, Australia, was obtained from all participants. Further details regarding sample ascertainment and collection are presented in related publications $[3,18]$.

\section{Measures}

Diagnostic interviews were based on the Semi-Structured Assessment for the Genetics of alcoholism (SSAGA) [19], which was updated for DSM-IV and adapted for telephone use in the Australian sample. ND measures were adapted for inclusion from the CIDI [20].

\section{Early cannabis use (EC)}

Self-reports of having used cannabis at least once prior to age 17: a definition shown previously by us to be associated highly with other illicit drug use [3].

\section{Nicotine dependence (ND)}

Individuals were coded as meeting criteria for DSM-IV nicotine dependence if they reported experiencing three or more of the seven diagnostic criteria within the same 12-month period.

Individuals who had smoked cigarettes at least once in their life-time, but did not endorse smoking cigarettes 100 or more times [21] during their life-time, were not queried about ND symptoms. These individuals were coded as unaffected for DSM-IV ND.

\section{Covariates}

To account for known correlates that may potentially mediate the association between EC and ND, we controlled for (i) DSM-IV major depression: the association between depression and ND has been studied extensively (e.g. [22-24] with evidence for common genetic influence. While the association between depression and cannabis use is controversial (see [25] for a review) genetic studies hint at some overlap [26,27], making this a potential mediating measure. (ii) Two or more DSM-IV conduct problems: if the association between EC and ND represents a general proneness to delinquent behavior [28], including substance use, then controlling for a history of conduct problems is important. (iii) Social 
anxiety (defined as experiencing fears, where doing something embarrassing/humiliating caused anxiety, or if experiencing fears caused problems with family, friends, work or other situations): individuals with social anxiety tend to smoke cigarettes more frequently [29]. (iv) Exposure to childhood sexual abuse (self-reported rape or molestation or forced sexual contact with someone within or outside the family, prior to 17 years of age), which has been shown to be a potent risk factor for early onset of substance use and later dependence [30-35]. (v) Life-time use of other illicit psychoactive substances (cocaine, sedatives, stimulants, inhalants, solvents, opiates, hallucinogens or phencyclidine), which has been demonstrated to be an important outcome of EC [3-6], with common genetic underpinnings. (vi) Early drinking (drinking alcohol at least once a month for 6 months or longer when aged 16 years or younger) and early smoking (smoking at least once a week for 3 weeks or longer at age 15 or younger), as EC may simply be a marker for early onset of multiple substances [36].

\section{Sample characteristics}

The full sample $(n=6257)$ had a mean age of 30 years and $44.8 \%$ were male. Other characteristics are presented elsewhere [18]. Almost $89 \%$ of the full sample reported experimenting with cigarettes (3028 male and 2554 female twins) (see previous reports [15,37]. Of these ever-smokers, $56.7 \%$ reported smoking 100 or more cigarettes in their life-time and $34.4 \%$ met criteria for DSM-IV ND [mean age of onset 21.2 (range 5-34 years)]. In the full sample, $60.2 \%$ reported a life-time history of cannabis use with $53.7 \%$ of these users $(15.6 \%$ of the population) reporting initiation prior to 17 years of age [mean age of onset 15.2 (range 9-16 years)]. In eversmokers, the prevalence of EC was $19 \%$ and $12.7 \%$ in men and women, respectively. Similarly, in individuals who reported experimentation with cigarettes and a lifetime history of cannabis use, the prevalence of ND was $42.8 \%$.

Nearly $83 \%$ of all participants reported initiating cigarette smoking prior to 17 years of age. About $55 \%$ of the sample reported having smoked $100+$ cigarettes prior to 17 years - these individuals are not informative in the discordant twin design and it is for this reason that we chose not to examine the association between EC and this measure. For ND, eight (additionally, six did not report an age of onset) of the EC users reported onset of ND prior to EC and were deleted from those discordant twin analyses.

The mean age of twins constituting the discordant pairs was 30 years [standard deviation (SD) 2.5] and $47.2 \%$ of the sample was male; $28.7 \%$ of the respondents had 10 or fewer years of education, while $25.7 \%$ reported tertiary education (i.e. going to university). About $46 \%$ of the sample reported being married (or widowed), while $44 \%$ were never married and the remainder were separated or divorced at the time of interview. These estimates were highly comparable to the full sample.

\section{Statistical methods}

\section{Discordant twin design}

To control for initiation of cigarette smoking, we selected only those twins who reported ever smoking cigarettes. Self-reported age of onset of cannabis use was used to select two subsamples of discordant twin pairs:

1 A total of 286 (129 MZ and $157 \mathrm{DZ)} \mathrm{like-sex} \mathrm{pairs,}$ where one member reported EC while their co-twin reported cannabis use at a later age or did not report a life-time history of cannabis use (i.e. including lifetime non-users);

2 A total of 229 (104 MZ and 125 DZ) like-sex pairs, where one member reported EC while their co-twin reported cannabis use after age 16 (i.e. excluding lifetime non-user co-twins).

The discordant twin method is a simple extension of matched-pair conditional logistic regression where, along with matching for age and sex, there is also matching for other latent factors, such as genetic and familial environmental influences, which are shared by members of twin pairs. Kendler and colleagues [22] have presented previously the patterns of odds ratios (OR) that we might expect, depending on whether the association between EC and ND is due to genetic or environmental factors or both:

1 If the association between EC and ND is due exclusively to genetic factors that influence both EC and ND then the OR in MZ twins, who share all their genes (identical-by-descent), would not be significant. However, the OR would be elevated in DZ twins who are matched only for $50 \%$ of their genetic background;

2 If the association between EC and ND is due exclusively to shared environmental factors that influence both EC and ND, then we would expect no increase in the OR in either MZ or DZ discordant pairs, as both are assumed to share their familial environment equally. Presumably, when a combination of overlapping genetic and shared environmental influences is at play, we might expect some elevation in the DZ OR.

3 If the association between EC and ND is due neither to genetic nor shared environmental influences, but instead is due entirely to unmeasured individualspecific environmental factors, or represents a truly causal relationship, then both MZ and DZ ORs would be elevated. 
4 Finally, if familial (genetic and/or shared environmental) and individual-specific environmental factors contribute jointly to the relationship between EC and ND, then again, both MZ and DZ OR would be elevated; however, the MZ OR would be smaller in magnitude than the DZ OR.

It is important to note here that we are considering only pairs of twins discordant for EC and examining its association with ND in a conditional logistic regression framework (i.e. how likely is the EC member of a discordant pair to be ND and how likely is the non-EC member of a discordant pair likely to not be ND?).

Conditional logistic regression models were fitted in STATA. The within-pair association between EC and ND was examined in the first sample of twins where the unaffected co-twins included life-time cannabis non-users, and the association was then re-examined in the smaller sample where the co-twin population excluded life-time non-users. All models were adjusted for covariates. The significance of interactions between gender and EC and between zygosity and EC was tested. Analyses were re-performed in MZ and DZ pairs discordant for EC use separately to tease apart the role of familial versus causal/non-causal unmeasured environmental influences.

\section{Bivariate twin models}

To test the robustness of our results to analytical strategy, we fitted bivariate twin models utilizing data from the entire sample (i.e. not just pairs discordant for cannabis use), to examine the extent to which genetic (A), shared environmental (C) and non-shared environmental (E) factors were correlated across EC and ND. Figure 1 represents, using a path diagram, the within-twin (co-twin not shown) relationship tested in the bivariate model. In the figure, A1, C1 and E1, and A2, C2 and E2 are the genetic, shared and individual-specific influences on EC and ND, respectively. $\mathrm{Rg}$ represents the extent to which $\mathrm{A} 1$ and A2, the genetic influences on EC and ND, are correlated. $\mathrm{Rc}$ and Re are shared and individual-specific environmental correlations, respectively, between EC and ND. Note that A1, the genetic influences on EC, are correlated 1.0 and 0.5 (across-twin within-trait) across members of a pair of $\mathrm{MZ}$ and $\mathrm{DZ}$ twins, respectively, while Rg represents the within-twin across-trait correlation between EC and ND and may be multiplied suitably by 1.0 or 0.5 (MZ or DZ pair) to explain the across-twin across-trait correlation (i.e. the correlation between EC in twin 1 and ND in twin 2).

Analyses were conducted on both definitions of EC, i.e. where non-user co-twins were included as '0' and where they were set to missing. For primary analyses, ND was

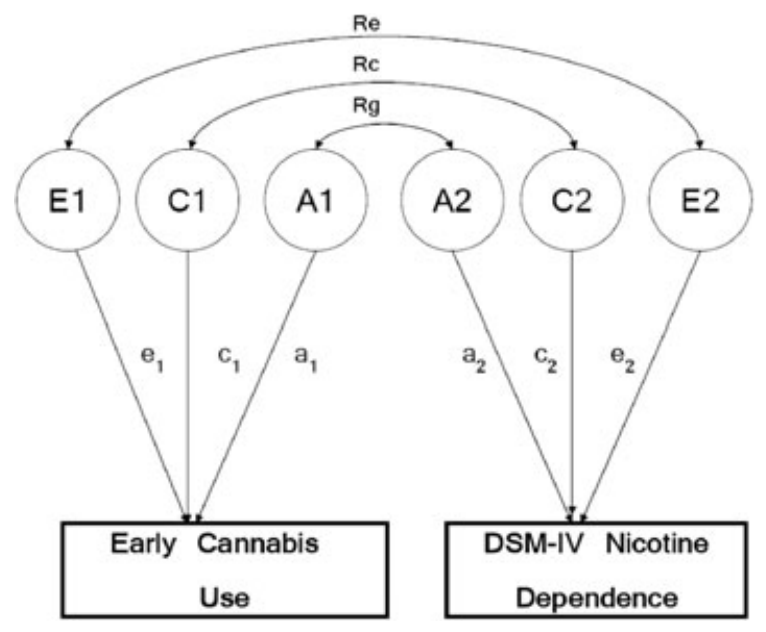

Figure I The bivariate twin model, represented as a path diagram (circles = latent variables; $\mathrm{A}=$ additive genetic, $\mathrm{C}=$ shared environment, $\mathrm{E}=$ individual-specific environment; rectangles = observed variable; double-headed arrows = correlations $\mathrm{Rg}, \mathrm{Rc}$ and $\mathrm{Re}$ ). Shown here for one twin only

set to missing in those who had never smoked even one cigarette - this is comparable to the discordant twin design. In secondary analyses, ND was set to missing in those who had never smoked cigarettes and in those who had smoked $<100$ cigarettes.

Models were fitted to raw data using a full information maximum-likelihood (FIML) estimation procedure using the software package Mx [38]. A, C and E were allowed to vary, in addition to thresholds, in male and female twins. The correlation across twins was allowed to vary from 0.5 in DZ opposite-sex twin pairs as a test for qualitative sex differences. The fit of submodels was tested using the difference in $-2 \log$-likelihood fit of the models, which follows a $\chi^{2}$ distribution $\left(\Delta \chi^{2}\right)$ for the given degrees of freedom $(\mathrm{df})$.

\section{RESULTS}

In this entire sample of twins, EC users were 2.7 [95\% confidence interval (CI) 2.3-3.3] times more likely to report ND even after controlling for psychiatric covariates.

\section{Discordant twin analyses}

The unadjusted odds of the EC twin meeting criteria for ND were 1.9. This increased likelihood of ND remained even after adjusting for substance use and comorbid psychopathology-EC twins, when compared to their lifetime non-user or later-onset user co-twin, were 1.7 times more likely to meet criteria for ND (Table 1). Interactions 
Table 1 Conditional odds ratio (OR) between early cannabis use and DSM-IV nicotine dependence in Australian same-sex twin pairs aged 24-36 years.

\begin{tabular}{|c|c|c|c|}
\hline & $\begin{array}{l}\text { Unadjusted ORs } \\
(95 \% \mathrm{CI})\end{array}$ & $\begin{array}{l}\text { Adjusted ORs } \\
(95 \% \mathrm{CI})\end{array}$ & Significant covariates \\
\hline $\begin{array}{l}\text { Including those who never used cannabis } \\
n=286 \text { pairs }\end{array}$ & $\begin{array}{l}1.9 \\
(1.3-2.8)\end{array}$ & $\begin{array}{l}1.8 \\
(1.1-2.7)\end{array}$ & $\begin{array}{l}\text { Early smoking, major depression, childhood } \\
\text { sexual abuse }\end{array}$ \\
\hline $\begin{array}{l}\text { Excluding those who never used cannabis } \\
n=229 \text { pairs }\end{array}$ & $\begin{array}{l}1.7 \\
(1.1-2.6)\end{array}$ & $\begin{array}{l}1.5 \\
(0.9-2.7)\end{array}$ & $\begin{array}{l}\text { Early smoking, major depression, childhood } \\
\text { sexual abuse }\end{array}$ \\
\hline
\end{tabular}

Covariates tested include DSM-IV major depression, 2+ conduct problems, social anxiety, exposure to childhood sexual abuse, life-time use of other illicit drugs, early drinking and early smoking. CI: confidence interval.

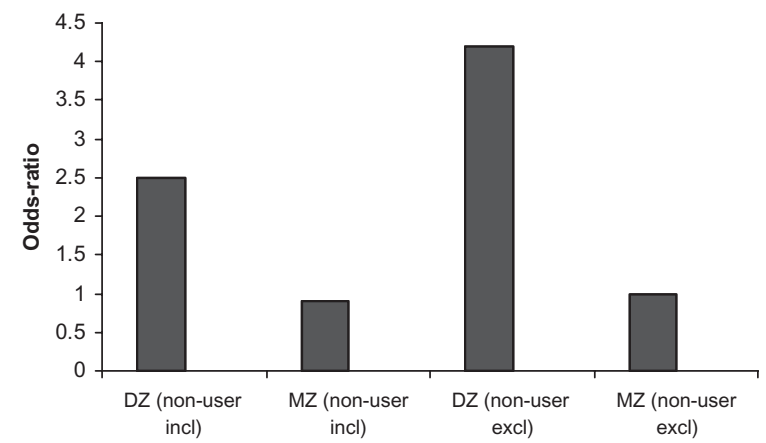

Figure 2 Pattern of monozygotic (MZ) and dizygotic (DZ) odds ratios for the association between early onset cannabis use and DSM-IV nicotine dependence in adult Australian same-sex twins pairs discordant for early cannabis use

between EC and gender or zygosity (being the member of a DZ versus MZ pair) were not significant.

Even upon exclusion of co-twins who had never used cannabis, EC users were still at 1.7 (95\% CI 1.1-2.6) greater odds for ND. After adjusting for covariates, this OR was not statistically significant (O.R. 1.5, 95\% CI 0.92.7, Table 1). Interactions with sex and zygosity were not significant.

Even though interactions with zygosity were not significant in either case, this may have been a consequence of reduced power. When we examined the ORs separately in discordant MZ pairs and DZ pairs, the association between EC (including or excluding cannabis non-user co-twins) and ND was significant only in DZ pairs (Fig. 2). The pattern of MZ-DZ ORs in Fig. 2 is consistent with the conclusion that the association between EC and ND is due to those factors that are correlated fully across MZ pairs (thus, there is no excess risk) but correlated only partially across DZ pairs (thus, the excess risk).

\section{Twin modeling}

Genetic (A) and non-shared environmental (E) factors influenced the liability to EC $\left(\mathrm{a}^{2}=72 \%\right.$ when non-users included; $\mathrm{a}^{2}=66 \%$ when non-users excluded) and to ND $\left(\mathrm{a}^{2}=48-58 \%\right.$ ) (Table 2$)$. There was no evidence for the
DZ opposite-sex correlation being different from the DZ same-sex twin correlation of 0.5 nor for varying magnitudes of $\mathrm{A}$ or $\mathrm{E}$ in men and women $\left(\Delta \chi^{2}=10.03\right.$ for 10 df). Shared environmental factors (C) could be dropped without a significant deterioration of fit $\left(\Delta \chi^{2}\right.$ ranged from 0 to 2.3 for $1 \mathrm{df}$ ). The total correlation between EC and ND was 0.34 when cannabis non-users were included and 0.23 when life-time non-users were excluded. This correlation could be attributed largely to overlapping genetic $(\mathrm{Rg}=0.52)$ factors even when non-users of cannabis were excluded $(\mathrm{Rg}=0.41)$. Consistent with findings from the discordant twin models, there was no evidence for $\operatorname{Re}\left(\Delta \chi^{2}=2.4\right.$ for $\left.1 \mathrm{df}\right)$, or those individualspecific environmental factors that make one member of an MZ twin pair report EC and progress to ND but does not impact their co-twin. Fitted statistics and the bestfitting model were largely unchanged when excluding non-users of cannabis from the definition of EC (Table 2).

To account for the variance due to smoking $100+$ cigarettes, ND was set to missing in those who had smoked less $<100$ cigarettes in their life-time and models were tested. As expected, this substantially reduced the heritability of ND $\left(\mathrm{a}^{2}=37 \%, 95 \%\right.$ CI $25-49 \%$, remainder due to $\mathrm{E})$ as well as the heritability of $\mathrm{EC}\left(\mathrm{a}^{2}=52 \%, 95 \%\right.$ CI $34-61 \%$, remainder due to $\mathrm{E}$ ). The genetic correlation between EC and ND was also reduced $(\mathrm{Rg}=0.24-0.35)$; however, the genetic correlations were statistically significant and there was no evidence for shared or individual-specific environmental correlations.

\section{DISCUSSION}

In this study of adult male and female twins, onset of cannabis use prior to 17 years of age (EC) increased the odds of DSM-IV ND. However, our analyses also revealed that this excess risk for ND in EC users was due largely to common genetic influences on EC and ND.

Several investigators have now demonstrated the increased risk of problematic cigarette smoking in those with a history of cannabis use [8,9,39-41]. In previous work by us concerning US women aged 18-29 years, 
Table 2 Results from best-fitting bivariate model assessing the relationship between early-onset cannabis use and DSM-IV nicotine dependence in adult Australian same- and opposite-sex twins with a life-time history of ever smoking cigarettes.

\begin{tabular}{|c|c|c|c|c|c|c|c|}
\hline & $\begin{array}{l}h^{2} \\
(95 \% C I)\end{array}$ & $\begin{array}{l}\chi^{2} \\
(95 \% C I)\end{array}$ & $\begin{array}{l}c^{2} \\
(95 \% C I)\end{array}$ & $R g$ & $R c$ & $\operatorname{Re}$ & $\begin{array}{l}\text { Total } \\
\text { covariance }\end{array}$ \\
\hline \multicolumn{8}{|c|}{ Early cannabis use including non-users } \\
\hline Early cannabis use & $\begin{array}{l}0.72 \\
(0.64-0.80)\end{array}$ & - & $\begin{array}{l}0.28 \\
(0.20-0.36)\end{array}$ & & - & - & \\
\hline Nicotine dependence & $\begin{array}{l}0.58 \\
(0.50-0.66)\end{array}$ & - & $\begin{array}{l}0.42 \\
(0.34-0.50)\end{array}$ & $\begin{array}{l}0.52 \\
(0.44-0.53)\end{array}$ & - & - & 0.34 \\
\hline \multicolumn{8}{|c|}{ Early cannabis use excluding life-time non-users } \\
\hline Early cannabis use & $\begin{array}{l}0.66 \\
(0.56-0.75)\end{array}$ & - & $\begin{array}{l}0.34 \\
(0.25-0.44)\end{array}$ & & & & \\
\hline Nicotine dependence & $\begin{array}{l}0.48 \\
(0.37-0.58)\end{array}$ & - & $\begin{array}{l}0.52 \\
(0.42-0.63)\end{array}$ & $\begin{array}{l}0.41 \\
(0.29-0.53)\end{array}$ & - & - & 0.23 \\
\hline
\end{tabular}

CI: confidence interval; Rg, Rc, Re: correlations.

who had used cannabis, were 2.8 times more likely to transition from smoking $100+$ cigarettes to ND [41]. There were, however, several limitations to these previous studies. First, none of these studies explored the possible role of EC, which is a potent predictor of other illicit drug use and psychopathology [3,27]. Secondly, none of them took into account the important etiological contributions of genetic influences and familial environment that may contribute, jointly, to risk for EC and also to progression to more involved stages of cigarette smoking, such as ND. If, indeed, the association between EC and ND extends beyond a shared genetic (and/or environmental) vulnerability, then reducing early exposure to cannabis use may also assist with lower rates of ND. As demonstrated by our study, the risk for ND that is attributable to $\mathrm{EC}$ can be attributed largely to the effects of common genetic factors. These common genetic influences overlap only partly with the prior stage of a life-time history of smoking $100+$ cigarettes.

This is the first study to document the effects of EC on ND using two complementary genetically informative methods. A feature of the current study is the consistency between the results of these two techniques: the discordant twin design and the bivariate twin model. While a twin model has been fitted previously to data on cannabis and cigarette smoking in adult female Virginia twins, it did not examine EC. These twin models are highly informative as they quantify the magnitude of genetic overlap between cannabis use and stages of cigarette smoking. As expected, these correlations were moderate to high, suggesting that there may exist a cluster of genetic factors that influence an early onset of cannabis use and also influence progression to ND and persistent smoking. This common vulnerability to cannabis and tobacco use has been identified across numerous twin studies $[17,42,43]$ and has been found to be influenced by genetic and shared environmental factors. It is plausible that the genetic influences on this non-specific component of risk may also extend to other aspects of disinhibited and externalizing behaviors [44-48] [for instance, gammaaminobutyric acid receptor A, subunit 2 (GABRA2)]. Identified initially for its role in alcohol dependence [49-52], recent work has implicated polymorphisms in the GABRA2 gene for their role in cannabis dependence [53], ND [54] and conduct disorder [55].

Genes common to cannabis and tobacco use alone, such as the cannabinoid receptor 1 (CNR1) gene may also contribute to the observed genetic correlation. As a target for endogenous cannabinoids [56], its role in mediating the effects of exogenous cannabinoids [57] is supported by animal [58,59] and human research, with some studies reporting association between polymorphisms in CNR1 and cannabis-related behaviors [60-62] but not others [63]. CB1/CNR1 receptors have also been implicated in ND. Nicotine increases levels of endogenous cannabinoids (e.g. anandamide) and influences reward sensitivity [64]. Rimonabant, a CB1 antagonist, is an emerging drug in tobacco cessation practice [65-70].

Some limitations to this study require discussion. First, our sample is an adult cohort of Caucasian men and women, and these findings may be sample-specific. Secondly, retrospective recall may have affected reports of cannabis use and cigarette smoking. Thirdly, we had fewer than 300 pairs of twins available for analysis, so power may be a concern.

In conclusion, after accounting for genetic commonality, there remains no compelling evidence for causal processes linking EC to ND. This does not imply that reducing rates of $\mathrm{EC}$ will have no impact on cigarette smoking behaviors. Instead, it suggests that use of cannabis at an early age may serve as a marker for genetic vulnerability to a host of substance use behaviors. 
Providing specialized preventive techniques to such vulnerable adolescents will reduce their general likelihood of progression within their cigarette smoking trajectories and will also probably reduce their levels of general drug involvement.

\section{Declarations of interest}

None.

\section{Acknowledgements}

This research is supported by DA023668 (A.A.), DA18660 and DA18267 (M.T.L.), DA019951 (M.L.P), DA12854 (PI Madden) and AA07728 (PI Heath), AA11998 (PI Heath) and AA13221 (PI Heath).

\section{References}

1. Kandel D. Stages and Pathways of Drug Involvement. New York, NY: Cambridge University Press; 2002.

2. Hall W., Lynskey M. Is cannabis a gateway drug: testing hypotheses about the relationship between cannabis use and use of other illicit drugs. Drug Alcohol Rev 2005; 24 : 39-48.

3. Lynskey M. T., Heath A. C., Bucholz K. K., Slutske W., Madden P. A., Nelson E. C. et al. Escalation of drug use in early-onset cannabis users vs co-twin controls. JAMA 2003; 289: 427-33.

4. Agrawal A., Neale M. C., Prescott C. A., Kendler K. S. A twin study of early cannabis use and subsequent use and abuse/ dependence of other illicit drugs. Psychol Med 2004; 34: 1227-37.

5. Lessem J. M., Hopfer C. J., Haberstick B. C., Timberlake D., Ehringer M. A., Smolen A. et al. Relationship between adolescent marijuana use and young adult illicit drug use. Behav Genet 2006; 36: 498-506.

6. Lynskey M., Vink J. M., Boomsma D. I. Early onset cannabis use and progression to other drug use in a sample of Dutch twins. Behav Genet 2006; 36: 195-200.

7. Patton G. C., Coffey C., Carlin J. B., Sawyer S. M., Wakefield M. Teen smokers reach their mid twenties. J Adolesc Health 2006; 39: 214-20.

8. Patton G. C., Coffey C., Carlin J. B., Sawyer S. M., Lynskey M. Reverse gateways? Frequent cannabis use as a predictor of tobacco initiation and nicotine dependence. Addiction 2005; 100: $1518-25$.

9. Timberlake D. S., Haberstick B. C., Hopfer C. J., Bricker J., Sakai J., Lessem J. et al. Progression from marijuana use to daily smoking and nicotine dependence in a national sample of U.S. adolescents. Drug Alcohol Depend 2007; 88: 272-81.

10. Agrawal A., Lynskey M. The genetic epidemiology of cannabis use, abuse and dependence: a review. Addiction 2006; 101: 801-12.

11. Madden P. A., Heath A. C., Pedersen N. L., Kaprio J., Koskenvuo M. J., Martin N. G. The genetics of smoking persistence in men and women: a multicultural study. Behav Genet 1999; 29: 423-31.

12. Sullivan P. F., Kendler K. S. The genetic epidemiology of smoking. Nicotine Tob Res 1999; 1 (Suppl 2): S51-S57.
13. Carmelli D., Swan G. E., Robinette D., Fabsitz R. Genetic influence on smoking - a study of male twins. N Engl J Med 1992; 327: 829-33.

14. Heath A. C. Persist or quit? Testing for a genetic contribution to smoking persistence. Acta Genet Med Gemellol (Roma) 1990; 39: 447-58.

15. Lessov C. N., Martin N. G., Statham D. J., Todorov A., Slutske W., Bucholz K. K. et al. Defining nicotine dependence for genetic research: evidence from Australian twins. Psychol Med 2004; 34: 865-79.

16. Pergadia M. L., Heath A. C., Martin N. G., Madden P. A. Genetic analysis of DSM-IV nicotine withdrawal in adult twins. Psychol Med 2006; 36: 963-72.

17. Neale M. C., Harvey E., Maes H. H., Sullivan P. F., Kendler K. S. Extensions to the modeling of initiation and progression: applications to substance use and abuse. Behav Genet 2006; 36: 507-24.

18. Heath A. C., Howells W., Kirk K. M., Madden P. A., Bucholz K. K., Nelson E. C., et al. Predictors of non-response to a questionnaire survey of a volunteer twin panel: findings from the Australian 1989 twin cohort. Twin Res 2001; 4: 73-80.

19. Bucholz K. K., Cadoret R. J., Cloninger R. C., Dinwiddie S. H., Hesselbrock V., Nurnberger J. I. et al. A New, semistructured psychiatric interview for use in genetic linkage studies. J Stud Alcohol 1994; 55: 149-58.

20. Cottler L. B., Robins L. N., Grant B. F., Blaine J., Towle S. H., Wittchen H. U. et al. The CIDI-core substance abuse and dependence questions: cross-cultural and nosological issues. The WHO/ADAMHA field trial. Br J Psychiatry 1991; 159: 653-8.

21. Centers for Disease Control and Prevention. Cigarette smoking among adults-United States, 1991. MMWR 1993; 42: 230-3.

22. Kendler K. S., Neale M. C., MacLean C. J., Heath A. C., Eaves L. J., Kessler R. C. Smoking and major depression. A causal analysis. Arch Gen Psychiatry 1993; 50: 36-43.

23. Johnson E. O., Breslau N. Is the association of smoking and depression a recent phenomenon? Nicotine Tob Res 2006; 8: 257-62.

24. Johnson E. O., Rhee S. H., Chase G. A., Breslau N. Comorbidity of depression with levels of smoking: an exploration of the shared familial risk hypothesis1. Nicotine Tob Res 2004; 6: 1029-38.

25. Degenhardt L., Hall W., Lynskey M. Exploring the association between cannabis use and depression. Addiction 2003; 98: 1493-504.

26. Fu Q., Heath A. C., Bucholz K. K., Nelson E., Goldberg J., Lyons M. J. et al. Shared genetic risk of major depression, alcohol dependence, and marijuana dependence: contribution of antisocial personality disorder in men. Arch Gen Psychiatry 2002; 59: 1125-32.

27. Lynskey M. T., Glowinski A. L., Todorov A. A., Bucholz K. K., Madden P. A. Nelson E. C. et al. Major depressive disorder, suicidal ideation, and suicide attempt in twins discordant for cannabis dependence and early-onset cannabis use. Arch Gen Psychiatry 2004; 61: 1026-32.

28. Donovan J. E., Jessor R. Structure of problem behavior in adolescence and young adulthood. J Consult Clin Psychol 1985; 53: 890-904.

29. Breslau N., Novak S. P., Kessler R. C. Psychiatric disorders and stages of smoking. Biol Psychiatry 2004; 55: 69-76.

30. Dembo R., Dertke M., La V. L., Borders S., Washburn M., Schmeidler J. Physical abuse, sexual victimization and illicit 
drug use: a structural analysis among high risk adolescents. J Adolesc 1987; 10: 13-34.

31. Harrison P. A., Fulkerson J. A., Beebe T. J. Multiple substance use among adolescent physical and sexual abuse victims. Child Abuse Negl 1997; 21: 529-39.

32. Neumann D. A., Houskamp B. M., Pollack V. E., Briere J. The long term sequelae of childhood sexual abuse in women. Child Maltreatment 1996; 1: 6-16.

33. Bushnell J. A., Wells J. E., Oakley-Browne M. A. Long-term effects of intrafamilial sexual abuse in childhood. Acta Psychiatr Scand 1992; 85: 136-42.

34. Dube S. R., Anda R. F., Whitfield C. L., Brown D. W., Felitti V. J., Dong M. et al. Long-term consequences of childhood sexual abuse by gender of victim. Am J Prev Med 2005; 28 : 430-8.

35. Nelson E. C., Heath A. C., Madden P. A., Cooper M. L., Dinwiddie S. H., Bucholz K. K. et al. Association between selfreported childhood sexual abuse and adverse psychosocial outcomes: results from a twin study. Arch Gen Psychiatry 2002; 59: 139-45.

36. Collins L. M., Graham J. W., Long J., Hansen W. B. Crossvalidation of latent class models of early substance use onset. Multivariate Behav Res 1994; 29: 165-83.

37. Pergadia M. L., Heath A. C., Agrawal A., Bucholz K. K., Martin N. G., Madden P. A. The implications of simultaneous smoking initiation for inferences about the genetics of smoking behavior from twin data. Behav Genet 2006; 36 : 567-76.

38. Neale M. C. Statistical modeling with Mx. Department of Psychiatry, Box \# 980710, Richmond VA 23298, USA, 2004.

39. Amos A., Wiltshire S., Bostock Y., Haw S., McNeill A. 'You can't go without a fag ... you need it for your hash'-a qualitative exploration of smoking, cannabis and young people. Addiction 2004; 99: 77-81.

40. Ream G. L., Benoit E., Johnson B. D., Dunlap E. Smoking tobacco along with marijuana increases symptoms of cannabis dependence. Drug Alcohol Depend 2008; 95: 199-208.

41. Agrawal A., Madden P., Bucholz K., Heath A., Lynskey M. Transitions to regular smoking and to nicotine dependence in women using cannabis. Drug Alcohol Depend 2008; 95 : $107-14$.

42. Han C., McGue M. K., Iacono W. G. Lifetime tobacco, alcohol and other substance use in adolescent Minnesota twins: univariate and multivariate behavioral genetic analyses. Addiction 1999; 94: 981-93.

43. Young S. E., Rhee S. H., Stallings M. C., Corley R. P., Hewitt J. K. Genetic and environmental vulnerabilities underlying adolescent substance use and problem use: general or specific?. Behav Genet 2006; 36: 603-15.

44. Krueger R. F., Hicks B. M., Patrick C. J., Carlson S. R., Iacono W. G., McGue M. Etiologic connections among substance dependence, antisocial behavior, and personality: modeling the externalizing spectrum. J Abnorm Psychol 2002; 111: 411-24.

45. Elkins I. J., King S. M., McGue M., Iacono W. G. Personality traits and the development of nicotine, alcohol, and illicit drug disorders: prospective links from adolescence to young adulthood. J Abnorm Psychol 2006; 115: 26-39.

46. Walden B., McGue M., Lacono W. G., Burt S. A., Elkins I. Identifying shared environmental contributions to early substance use: the respective roles of peers and parents. J Abnorm Psychol 2004; 113: 440-50.

47. Iacono W. G., Carlson S. R., Taylor J., Elkins I. J., McGue M. Behavioral disinhibition and the development of substance- use disorders: findings from the Minnesota twin family study. Dev Psychopathol 1999; 11: 869-900.

48. Kendler K. S., Prescott C. A., Myers J., Neale M. C. The structure of genetic and environmental risk factors for common psychiatric and substance use disorders in men and women. Arch Gen Psychiatry 2003; 60: 929-37.

49. Edenberg H. J., Dick D. M., Xuei X., Tian H., Almasy L., Bauer L. O. et al. Variations in GABRA2, encoding the alpha 2 subunit of the GABA(A) receptor, are associated with alcohol dependence and with brain oscillations. Am J Hum Genet 2004; 74: 705-14.

50. Fehr C., Sander T., Tadic A., Lenzen K. P., Anghelescu I., Klawe C. et al. Confirmation of association of the GABRA2 gene with alcohol dependence by subtype-specific analysis. Psychiatr Genet 2006; 16: 9-17.

51. Lappalainen J., Krupitsky E., Remizov M., Pchelina S., Taraskina A., Zvartau E. et al. Association between alcoholism and gamma-amino butyric acid alpha2 receptor subtype in a Russian population. Alcohol Clin Exp Res 2005; 29: 493-8.

52. Covault J., Gelernter J., Hesselbrock V., Nellissery M., Kranzler H. R. Allelic and haplotypic association of GABRA2 with alcohol dependence. Am J Med Genet B Neuropsychiatr Genet 2004; 129: 104-9.

53. Agrawal A., Edenberg H. J., Foroud T., Bierut L. J., Dunne G., Hinrichs A. L. et al. Association of GABRA2 with drug dependence in the collaborative study of the genetics of alcoholism sample. Behav Genet 2006; 36: 640-50.

54. Agrawal A., Pergadia M. L., Saccone S. F., Hinrichs A. L., Lessov-Schlaggar C. N., Saccone N. L. et al. Gammaaminobutyric acid receptor genes and nicotine dependence: evidence for association from a case-control study. Addiction 2008; 103: 1027-38.

55. Dick D. M., Bierut L. J., Hinrichs A. L., Fox L., Bucholz K. K., Kramer J. et al. The role of GABRA2 in risk for conduct disorder and alcohol and drug dependence across different developmental stages. Behav Genet 2006; 36: 577-90.

56. Devane W. A., Hanus L., Breuer A., Pertwee R. G., Stevenson L. A., Griffin G. et al. Isolation and structure of a brain constituent that binds to the cannabinoid receptor. Science 1992; 258: 1946-9.

57. Yamamoto T., Takada K. Role of cannabinoid receptor in the brain as it relates to drug reward. Jpn J Pharmacol 2000; 84: 229-36.

58. Zimmer A., Zimmer A. M., Hohmann A. G., Herkenham M., Bonner T. I. Increased mortality, hypoactivity, and hypoalgesia in cannabinoid CB1 receptor knockout mice. Proc Natl Acad Sci USA 1999; 96: 5780-5.

59. Lichtman A. H., Martin B. R. Cannabinoid tolerance and dependence. Handb Exp Pharmacol 2005; 168: 691-717.

60. Zhang P.W., Ishiguro H., Ohtsuki T., Hess J., Carillo F., Walther D. et al. Human cannabinoid receptor $1: 5^{\prime}$ exons, candidate regulatory regions, polymorphisms, haplotypes and association with polysubstance abuse. Mol Psychiatry 2004; 9: 916-31.

61. Hopfer C. J., Young S. E., Purcell S., Crowley T. J., Stallings M. C., Corley R. P. et al. Cannabis receptor haplotype associated with fewer cannabis dependence symptoms in adolescents. Am J Med Genet B Neuropsychiatr Genet 2006; 141: 895901.

62. Zuo L., Kranzler H. R., Luo X., Covault J., Gelernter J. CNR1 variation modulates risk for drug and alcohol dependence. Biol Psychiatry 2007; 62: 616-26

63. Herman A. I., Kranzler H. R., Cubells J. F., Gelernter J., 
Covault J. Association study of the CNR1 gene exon 3 alternative promoter region polymorphisms and substance dependence. Am J Med Genet B Neuropsychiatr Genet 2006; 141: 499-503.

64. Siu E. C., Tyndale R. F. Non-nicotinic therapies for smoking cessation. Annu Rev Pharmacol Toxicol 2007; 47: 54164.

65. Gelfand E. V., Cannon C. P. Rimonabant: a selective blocker of the cannabinoid $\mathrm{CB} 1$ receptors for the management of obesity, smoking cessation and cardiometabolic risk factors. Expert Opin Investig Drugs 2006; 15: 307-15.

66. Le F. B., Goldberg S. R. Rimonabant, a CB1 antagonist, blocks nicotine-conditioned place preferences. Neuroreport 2004; 15: 2139-43.
67. Castane A., Valjent E., Ledent C., Parmentier M., Maldonado R., Valverde O. Lack of CB1 cannabinoid receptors modifies nicotine behavioural responses, but not nicotine abstinence. Neuropharmacology 2002; 43: 857-67.

68. Garwood C. L., Potts L. A. Emerging pharmacotherapies for smoking cessation. Am J Health Syst Pharm 2007; 64: 1693-8.

69. Cahill K., Ussher M. Cannabinoid type 1 receptor antagonists (rimonabant) for smoking cessation. Cochrane Database Syst Rev 2007, Issue 4; CD005353. DOI: 10.1002/ 14651858.CD005353.pub3

70. Muccioli G. G. Blocking the cannabinoid receptors: drug candidates and therapeutic promises. Chem Biodivers 2007; 4: 1805-27. 